\title{
Recently widowed people were at greater risk of dying than married people
}

Lichtenstein P, Gatz M, Berg S. A twin study of mortality after spousal bereavement. Psychol Med 1998 May;28:635-43.

Question

What are the effects of spousal bereavement on mortality?

Design

Cohort analysis including a co-twin control analysis.

\section{Setting}

Community based study in Sweden.

\section{Participants}

35860 people (52\% women) who were born between 1886 and 1958. Cohort 1 included people born between 1886 and 1925 $(\mathrm{n}=10040$, mean age $65 \mathrm{y}$ in men and $66 \mathrm{y}$ in women) and cohort 2 included people born between 1926 and 1958 $(\mathrm{n}=35852$, mean age $40 \mathrm{y}$ in men and $39 \mathrm{y}$ in women).

\section{Assessment of risk factors}

Data on marital status and date of death were obtained by linking the Swedish population registry and the cause of death registry. Data on twins were obtained from the Swedish Twin Registry. Questionnaires issued every few years from 1961 provided information on health and health related risk factors. These included smoking status, alcohol consumption, education, body mass index, cardiovascular disease, respiratory disease, and other chronic disease.

\section{Main outcome measure}

Mortality in widowed people compared with married people.

\section{Main results}

The study sample was analysed in 2 age groups: young-old ( $\leqslant 69$ y) and old-old $(\geqslant 70 \mathrm{y})$. Mortality was higher in widowed people than in married people, particularly in the young-old who were bereaved for $<6$ months (relative hazard [RH] of death in men $2.68,95 \%$ CI 1.20 to 5.97 and in women 2.35 , CI 1.26 to 4.40 ). The mortality rate decreased the longer the widowed people were followed after their spouse's death. In young-old widows who survived $>4$ years after bereavement, the $\mathrm{RH}$ of death was lower than that of married women (RH 0.60, CI 0.41 to 0.88 ). Sufficient questionnaire data were available for cohort 1 to do a covariate analysis controlling for other risk factors. The survival pattern was not substantially affected and still showed a greater mortality rate in recently bereaved young-old people and greater survival in young-old widows who were bereaved $>4$ years before. The co-twin control analysis confirmed the results. Recently widowed people had a greater risk of death than married people, the risk decreased the longer the period of time from bereavement, and young-old women who were widowed $>4$ years had a lower risk of death than their married twins $(\mathrm{RH}$ 0.48 , CI 0.23 to 0.98 ).

\section{Conclusions}

The mortality risk in recently widowed people who were $\leqslant 69$ years of age was greater than in married people. Widowed women who survived longer than 4 years after bereavement had a lower risk of dying than married women.

Source of funding: Swedish Council for Social Research.

For correspondence:Dr P Lichtenstein, Institute of Environmental Medicine, The Karolinska Institute, Box 210, S-17177 Stockholm, Sweden. Fax +468304571.

\section{Commentary}

The sophisticated and carefully executed epidemiological investigation by Lichtenstein et al provides strong evidence that spousal bereavement increases mortality among older people, especially young-old women $\leqslant 69$ years of age. By comparing survival rates between bereaved and still married twins, the authors effectively control for several constitutional and early life risk factors that might otherwise threaten the validity of their results (ie, factors that might compromise long term survival independently of the stressors associated with bereavement). The inclusion of other prognostic indicators (eg, smoking, body mass index, and cardiovascular disease) also helps to rule out alternative interpretations. Thus, the subset of findings in which such sampling and statistical controls could be incorporated provides the most compelling evidence in this report.

Controlling for prognostic factors, the overall pattern of survival among youngold people conformed to that described, but the finding was statistically significant in only 4 of 8 comparisons against population norms. Among the old-old, it was statistically significant in only 1 of 8 . Even fewer comparisons met this criterion when these analyses were repeated to compare survival across bereaved and non-bereaved twins. Psychosocial influences on mortality are subtle and difficult to detect. Given the careful methodology and huge subject pool ( $>36000$ people over 100 years), these findings provide compelling evidence that spousal bereavement is importantly linked to mortality. The absence of a more consistent pattern, however, also hints that the causal mechanism is complex and multifactorial.

Considerable evidence links the availability of social support to survival, and this effect can be more powerful than established prognostic factors (eg, smoking, obesity, or alcohol). ${ }^{1}$ Involvement in meaningful social relationships can promote survival. ${ }^{2}$ Evidence from chronic disease populations also indicates that mortality can be reduced by routine stress monitoring, ${ }^{3}$ regular telephone contact, ${ }^{4}$ and participation in support groups. ${ }^{5}$ Continued involvement in valued activities and interests provides another important mechanism for promoting psychosocial adaptation. ${ }^{6}$ Efforts to enlist loved ones and significant others in providing needed support and encouragement to carry on after bereavement can thus help to promote survival and simultaneously facilitate the resolution of grief.

Gerald M Devins, PhD, CPsych Centre for Addiction and Mental Health Toronto, Ontario, Canada

\footnotetext{
1 Berkman LF, Syme SL. Am J Epidemiol 1979;109:186-204.

2 House JS, Robbins C, Metzner HL. Am J Epidemiol 1982;116:123-40.

3 Frasure-Smith N, Prince R. Psychosom Med 1989;51:485-513.

4 Wasson J, Gaudette C, Whaley F, et al. JAMA 1992;267: 1788-93.

5 Friend R, Singletary Y, Mendell NR, et al. Am J Public Health 1986;76:670-2.

6 Devins GM, Mann J, Mandin H, et al. J Nerv Ment Dis 1990;178:127-33.
} 